\title{
Bringt zusammen, was zusammengehört: die Stellenbörse der DRG
}

Sie suchen Fachpersonal - oder sind selbst auf der Suche nach einer neuen beruflichen Herausforderung? Die Lösung für beides: ein Blick in die Stellenbörse für Radiologie, Nuklearmedizin, Strahlentherapie, Strahlenbiologie, -physik und -technik. Nutzen Sie die Stellenbörse der Deutschen Röntgengesellschaft für optimale Zielgruppendurchdringung!

\section{Stellenausschreibungen}

In der Stellenbörse der DRG finden Sie aktuelle Stellenangebote aus dem Bereich der Radiologie. Wenn Sie eine Anzeige veröf- fentlichen möchten, nutzen Sie bitte das entsprechende Online-Formular (drg.de> Über uns > Stellenbörse > Schreiben Sie eine Stelle aus).

Wählen Sie aus unserem Angebot

\begin{tabular}{|l|l|}
\hline Laufzeit & Preis \\
\hline 3 Monate & $300,00 €$ \\
\hline 6 Monate & $400,00 €$ \\
\hline 12 Monate & $650,00 €$ \\
\hline
\end{tabular}

Alle Preise verstehen sich zuzüglich $19 \%$ MwSt.

Bei Fragen steht Ihnen Frau Strauß gerne zur Verfügung (Email: strauss@drg. de, Tel.: 030/91607 033).

Alle weiteren Informationen finden Sie auf drg.de > Wir über uns $>$ Stellenbörse 